\title{
Effects of grass shrimp versus nutrient addition on epiphytic algae associated with the ephemeral widgeongrass Ruppia maritima
}

\author{
Donna Drury McCall ${ }^{1,3, *}$, Chet F. Rakocinski ${ }^{1}$, James L. Pinckney ${ }^{2}$ \\ ${ }^{1}$ Gulf Coast Research Laboratory, Department of Coastal Sciences, University of Southern Mississippi, 703 E. Beach Drive, \\ Ocean Springs, Mississippi 39564, USA \\ ${ }^{2}$ Department of Biological Sciences and Marine Science Program, University of South Carolina, Columbia, \\ South Carolina 29208, USA
}

${ }^{3}$ Present address: Tulane University, School of Continuing Studies, 2600 Beach Blvd., Biloxi, Mississippi 39531, USA

\begin{abstract}
Grazers can reduce epiphytic algal loads on submerged aquatic vegetation (SAV) and indirectly alter biotic interactions among epiphytic algal groups. In the present study, we elucidate responses by 3 major epiphytic functional groups (diatoms, rhodophytes, and chlorophytes) to grass shrimp Palaemonetes spp. addition and nutrient addition during 3 growth stages of the ephemeral estuarine SAV, Ruppia maritima. Three field experiments conducted in the Grand Bay National Estuarine Research Reserve, Mississippi, USA, revealed that grass shrimp altered the community composition of epiphytic algae mainly in the mid- and late-growth stages by selectively grazing red algal epiphytes. Corresponding diatom and green algal responses likely reflect release from biotic interactions, or possibly secondary shrimp feeding preferences. Except for a modest but significant increase in red algae relative to shrimp addition, which did not reflect effects of grazing, epiphyte groups did not respond noticeably to shrimp addition in the early stage experiment. Grass shrimp addition appeared to be more important in shaping epiphytic algal composition than nutrient addition. Enclosure effects possibly influenced algal growth and shrimp addition effects. Changes in the composition of the epiphyte community relative to nutrient addition were modest and variable. The lack of significant shrimp-nutrient interactions across all 3 experiments reflected primarily independent effects of both factors on epiphyte composition. Disproportionate effects of grass shrimp on the SAV epiphyte community, as expressed within the context of the inherently plastic and complex trophic role played by these facultative grazers, should help maintain the diversity and function of structured SAV habitats.
\end{abstract}

KEY WORDS: Submerged aquatic vegetation (SAV) $\cdot$ Ruppia maritima $\cdot$ Grass shrimp $\cdot$ Epiphytic algae Grazing $\cdot$ Nutrient addition

Resale or republication not permitted without written consent of the publisher

\section{INTRODUCTION}

Declines in estuarine habitats with submerged aquatic vegetation (SAV) reflect the detrimental effects of nutrient-induced epiphytic algal overgrowth (Wear et al. 1999), deficient epiphyte grazer responses (Neckles et al. 1993, Williams \& Heck 2001), or both top-down and bottom-up effects of coastal eutrophication (Drury McCall \& Rakocinski 2007). Epiphyte pro- ductivity and composition may be affected by grazing and nutrient enrichment (van Montfrans et al. 1984, Hillebrand \& Sommer 1997). For example, grazing can stimulate epiphytic algal productivity (QuiñonesRivera \& Fleeger 2005). Besides exerting direct control on epiphyte loading, grazing may indirectly maintain epiphyte diversity on SAV (Jernakoff et al. 1996). In the western Baltic Sea, nutrient loading leads to increased consumption of microphytobenthos by crus- 
tacean and gastropod grazers (Hillebrand et al. 2000), suggesting a compensatory link between producers and consumers in response to eutrophication.

Algal epiphytes can also enhance the health of the host macrophyte. Epiphytic algae may exchange metabolites and nutrients with their SAV hosts (Pinckney \& Micheli 1998). Moderate epiphyte biomass may protect the host macrophyte from desiccation, and epiphytic cyanobacteria can provide low concentrations of fixed nitrogen (Moncreiff et al. 1992, Williams \& Ruckelshaus 1993). Consequently, a diverse SAV-epiphytic algal association helps to maintain healthy seagrass habitats (Moncreiff et al. 1992).

The ephemeral euryhaline SAV Ruppia maritima occurs from late spring through early winter in temperate estuaries (Kantrud 1991). This macrophyte exhibits distinct growth stages, ending with the onset of senescence, which entails the die-back of aboveground biomass. The lack of reproductive shoots signals the early $R$. maritima growth stage; the appearance of reproductive shoots signals the mid-growth stage; and a high density of reproductive shoots throughout the $R$. maritima bed signals the late-growth stage. Senescence is a normal part of the $R$. maritima life cycle, but premature die-back can occur when a dense coat of epiphytic algae suppresses photosynthetic efficiency under eutrophic conditions (Kantrud 1991). Diatoms, rhodophytes (red algae), and chlorophytes (green algae) comprise the major functional groups within the $R$. maritima epiphyte community (Sullivan 1977, Drury 2004). The composition of epiphyte functional groups may also change with the life stage of this host macrophyte, for example, because the epiphyte community may partially depend on $R$. maritima for nutrients (Sullivan 1977).

A predominant nekton taxon ranging from Nova Scotia to Texas, the grass shrimp Palaemonetes spp., enhances the efficiency of energy and nutrient transfer within estuarine ecosystems through feeding and excretion (Welsh 1975). Although omnivorous, grass shrimp facultatively consume significant quantities of epiphytic diatoms and filamentous red algae (Morgan \& Kitting 1984, Fleeger et al. 1999, Quiñones-Rivera \& Fleeger 2005). Grass shrimp also enhance SAV condition by grazing excess epiphytic algae and possibly by translocation of feces to sediments (Johannes \& Satomi 1966, Drury McCall \& Rakocinski 2007). Grazing (either selective or non-selective) and excretion by grass shrimp may also influence the composition of the epiphytic algal community, and possibly help maintain diverse and productive SAV habitats within estuarine ecosystems.

In a previous study (Drury McCall \& Rakocinski 2007), we found that grass shrimp Palaemonetes spp. play a pivotal trophic role in the ephemeral Ruppia maritima habitat through context-dependent interactions involving the stage of the SAV life cycle, season, and nutrient supply. Epiphyte grazing by grass shrimp inhibited SAV die-back during the mid- and late-growth stages of the $R$. maritima life cycle. Nutrient addition significantly increased epiphyte algal biomass during the early stage of the SAV life cycle, when the effects of shrimp grazing were not apparent. Other studies have examined links between nutrient enrichment, algal epiphyte dynamics, and epiphyte grazing (Neckles et al. 1993, Williams \& Ruckelshaus 1993, Duffy et al. 2001). However, few studies have considered the relative importance of SAV-associated grazer and nutrient effects on the composition of epiphytic functional groups (but see Neckles et al. 1994), and even fewer studies have examined such trophic interactions in situ. Furthermore, the SAV life stage has rarely been considered when assessing the importance of grazing or nutrients on epiphytic community structure. Herein, we examined the joint effects of grass shrimp and nutrient addition on the epiphyte community of an ephemeral estuarine SAV using in situ field experiments conducted during 3 SAV growth stages.

\section{MATERIALS AND METHODS}

Field experiments. Three field experiments were conducted in Middle Bay within the Grand Bay National Estuarine Research Reserve (GB NERR), Jackson County, Mississippi, USA (see Ecological Archives E088-041-A1 and -A2 for GB NERR map and study site information). Each experiment was conducted during a distinct growth stage of Ruppia maritima, as defined by the season and occurrence of reproductive shoots (Kantrud 1991). The first experiment (mid-stage; $30^{\circ} 21.204^{\prime} \mathrm{N}, 88^{\circ} 23.619^{\prime} \mathrm{W}$ ) was started on 6 June 2001 during the mid-growth stage, the second experiment (late-stage; $30^{\circ} 21.604^{\prime} \mathrm{N}, 8^{\circ} 23.873^{\prime} \mathrm{W}$ ) was started on 8 August 2001 during the late-growth stage, and the third experiment (early-stage; $30^{\circ} 21.664^{\prime} \mathrm{N}$, $88^{\circ} 23.878^{\prime} \mathrm{W}$ ) was started on 9 May 2002 during the early-growth stage. Henceforth, we refer to the 3 experiments as early-stage, mid-stage, or late-stage.

For each of the 3 experiments, Ruppia maritima was enclosed in situ within acrylic cylinders in a split-plot configuration across 3 sites (i.e. blocks). The sites were $50 \mathrm{~m}$ apart, positioned along the $1 \mathrm{~m}$ depth contour, and located 50 to $100 \mathrm{~m}$ from the shore (Ecological Archives E088-041-A3 and -A4 for diagram of layout and experimental assembly protocol). Sites (i.e. blocks) delineated 4 'plots' placed at the corners of a $5 \mathrm{~m}$ square area; each plot comprised 3 cylinders and an unenclosed 'control' area. Each cylinder $(14.6 \mathrm{~cm}$ inside diameter, $0.91 \mathrm{~m}$ high, $0.015 \mathrm{~m}^{3}$ volume) enclosed 10 shoots of $R$. maritima within a $0.017 \mathrm{~m}^{2}$ area. Ambient water flowed through eight $1.8 \mathrm{~mm}$ Nitex mesh-covered holes $(7.62 \mathrm{~cm}$ diameter), and wells at 
the sediment interface precluded complete drainage during extreme low tides. Two plots at opposing corners of each site received nutrient addition, and each cylinder within a plot randomly received 1 of 3 grass shrimp Palaemonetes spp. treatments: no (0 shrimp), medium (3 shrimp), or high (10 shrimp) (Ecological Archives E088-041-A3 for experiment assembly). Each experiment was run for $28 \mathrm{~d}$ and potentially yielded a total of 60 samples (i.e. 12 time-zero samples and 48 experimental samples, including 12 control samples and 36 cylinder samples comprising 3 sites $\times 4$ plots $\times$ 3 grass shrimp treatments). Grass shrimp recovery and processing protocols are detailed in Ecological Archives E088-041-A5.

Laboratory methodology. Processing of each Ruppia maritima sample involved enumerating shoots and taking their dry and ash-free dry weights (Ecological Archives E088-041-A5 and -A6). The presence of major epiphytic algal groups $(n=20$ randomly selected samples) was also determined visually using a microscope for each experiment. For each sample, epiphytic material was scraped from each of 10 (or less) shoots, and total shoot surface area was measured. Epiphytic material was concentrated to form a suspension containing $3 \mathrm{ml}$ of filtered study-site water in a covered watchglass. Suspensions were filtered on Whatman GF/F 42 mm filters using a Fisher 3-way filtration manifold and vacuum pump. Filters were folded in half and blotted with a paper towel to remove excess moisture, wrapped in aluminum foil, labeled, and kept frozen at $-70^{\circ} \mathrm{C}$ until analyzed using high-performance liquid chromatography (HPLC; Shimadzu system).

HPLC analysis. Protocols for photopigment extraction followed the methods outlined by Pinckney et al. (1996). Epiphyte samples for HPLC processing were thawed for approximately $20 \mathrm{~min}$. Sample filters were patted dry to remove excess moisture and sliced into fine strips. Strips were then placed in labeled disposable $2 \mathrm{ml}$ polypropylene plastic microcentrifuge tubes to which $1 \mathrm{ml}$ of $100 \%$ acetone was added, and the samples were sonicated (Fisher Sonic Dismembrator Model 300, with microtip) to facilitate photopigment extraction. Tubes were held overnight (approximately $12 \mathrm{~h}$ ) in $\mathrm{a}-20^{\circ} \mathrm{C}$ freezer to further promote pigment extraction. The supernatant was filtered through a $0.45 \mu \mathrm{m}$ PTFE filter (Gelman Acrodisc), and $0.75 \mathrm{ml}$ of extract was placed into labeled amber glass autosampler vials $(2.0 \mathrm{ml})$ and held at $-20^{\circ} \mathrm{C}$ until analyzed with HPLC. Photopigment separation involved a combination of the Mantoura \& Llewellyn (1983) and van Heukelem et al. $(1992,1994)$ protocols.

Data analysis and interpretation. Of the many algal pigments that were detected by HPLC, 4 dominant pigments were quantified: total chlorophyll a ( $\mathrm{chl} a)$, fucoxanthin (fuco), zeaxanthin (zea), and chlorophyll $b$ (chl b) (i.e. marker pigments for the amounts of total algae, diatoms, red algae/cyanobacteria, and green algae, respectively). Although zeaxanthin is a marker pigment for both red algae and cyanobacteria, microscopic analysis of experimental Ruppia maritima samples revealed diatoms, large quantities of red algae, and green algae as the primary functional epiphyte groups. Log-transformed pigment concentration values (i.e. In scale) were generally normally distributed; non-detect pigment observations were replaced by appropriately small values (i.e. mean - 2.5 SD) obtained from the distribution of transformed values.

Marker pigments were scaled relative to total chl a and to the other marker pigments (i.e. coupled pigment variables) as log ratios (i.e. ln Pigment 1-ln Pigment 2). Scaling marker pigments to chl a standardized their concentrations relative to the total amount of epiphytic algae, whereas scaling of coupled marker pigments enabled detection of joint responses in the epiphytic functional groups. The statistical properties of log ratios are robust and amenable to parametric statistics (Elston et al. 1996, Schedl 1998), typically showing even better agreement with parametric assumptions than individual log values. Moreover, unlike proportions, log ratios of compositional variables do not exhibit spurious correlations (Schedl 1998).

Pigment responses were examined within a split-plot analysis of variance (ANOVA) design (Mead et al. 2003) using the multivariate analysis of variance syntax in SPSS (SPSS 15.0). Variance was partitioned into main-plot and split-plot portions: the main-plot portion comprised the random site factor $(n=3)$ and the fixed nutrient factor $(n=2)$. The site $\times$ nutrient interaction term served as the main-plot error. The split-plot portion comprised the fixed shrimp factor $(\mathrm{n}=4)$, as well as the shrimp $\times$ nutrient interaction term. The split-plot error term took up the remaining degrees of freedom.

All ANOVA effects involving the split-plot error term, including shrimp, shrimp $\times$ nutrient, and site $\times$ nutrient effects, were tested as multivariate responses for the 2 groups of pigment variables (marker pigments and coupled pigments). Separate multivariate analyses were run for the 3 marker pigments scaled to total chl $a$, as well as for 2 of the coupled pigment variables. Only 2 of the 3 possible coupled pigment variables were required for multivariate tests, as the third coupled pigment variable was linearly dependent on the other 2 coupled variables. Multivariate significance was based on F-tests of Pillai's trace values. Bartlett's tests of sphericity assessed the homogeneity of the covariance matrix assumption for multivariate tests. Multivariate tests of site and nutrient main effects were precluded by the split-plot design. However, univariate tests of pigment variables were possible for all terms. Cochran's tests addressed homogeneity of vari- 
ance in pigment responses among treatment groups within univariate ANOVAs. Effect sizes (partial etasquared $\left[\eta_{\mathrm{P}}^{2}\right]$ or eta-squared $\left.\left[\eta^{2}\right]\right)$ accompanied multivariate and univariate tests for all terms in the splitplot model.

Planned orthogonal contrasts relative to grass shrimp treatment effects were also conducted for the pigment variables within the split-plot ANOVA. Three research hypotheses specified contrasts at the protected Type I error rate (Sokal \& Rohlf 1981). Orthogonal contrasts specified enclosure $(3,-1,-1,-1)$, shrimpaddition $(0,2,-1,-1)$, and shrimp-density $(0,0,1,-1)$ effects. Parenthetical contrast coefficients reflect weights applied to comparisons of treatment means, and order of contrasts parallels that of treatment levels: control (ambient), no (0 shrimp), medium (3 shrimp), high (10 shrimp). Because orthogonal contrasts simply represent partitioning of the variance attributable to the factor of concern, they can be interpreted regardless of whether the overall F-test of that factor is significant (Quinn \& Keough 2002), thus enabling insights into the significance of specific hypothetical effects. In addition to $t$-tests of the research hypotheses, $\eta^{2}$ effects were also calculated for each of the contrasts. Treatment effects were deemed to be significant at $\mathrm{p}<0.06$ (i.e. to balance Type I and Type II error) and marginally significant at $\mathrm{p}<0.10$.

\section{RESULTS}

\section{Split-plot effects}

Multivariate tests

Multivariate tests on linear combinations of the 3 standardized marker pigments representing functio- nal groups of epiphytic algae were significant for the shrimp factor in all 3 experiments (Table 1). Multivariate tests of coupled pigments were significant for mid- and late-stage experiments. Non-significant Bartlett's tests of sphericity for multivariate tests supported the homogeneity of variance-covariance matrix assumption for all 3 experiments: $F$-values ranged from $2.137(\mathrm{p}=0.544)$ to $7.000(\mathrm{p}=0.072)$ across experiments. Effect sizes $\left(\eta^{2}\right)$ for the shrimp factor ranged from 0.160 to 0.220 of the multivariate variance representing the 3 scaled marker pigments, and from 0.133 to 0.264 for that representing the 2 coupled pigments.

Multivariate tests on linear combinations of marker pigments and coupled pigments were not significant for the shrimp $\times$ nutrient term in any of the 3 experiments (Table 1). Effect sizes $\left(\eta^{2}\right)$ were accordingly low for the shrimp $\times$ nutrient term in all 3 experiments, ranging from 0.026 to 0.132 of the variance in marker and coupled pigments across experiments. The site $\times$ nutrient term was notably significant $(p=0.002)$ in the late-stage experiment for marker pigments, primarily reflecting among-site differences in the effect of nutrients on fucoxanthin (diatoms).

\section{Grass shrimp addition}

Follow-up univariate split-plot ANOVAs of the shrimp (Palaemonetes spp.) factor were significant for 5 of the 6 pigment variables in the mid-stage and latestage experiments, and for 1 of the 6 variables in the early-stage experiment (Table 2). Cochran's tests indicated homogeneous variance for all 6 pigment variables (marker and coupled variables) in the mid-stage experiment $\left(C_{1,23}=0.300\right.$ to $0.169 ; \mathrm{p}=0.130$ to 1.00$)$ and for all pigment variables, except chl $b$-chl $a$ and

Table 1. Multivariate tests of split-plot terms for linear combinations of the marker pigments in the 3 field experiments; test values are based on Pillai's trace. Multivariate tests of site and nutrient main effects are not available (NA). (Fuco + Zea + Chl $b$ ) $-\mathrm{Chl} a$ : multivariate response representing the 3 primary marker pigments fucoxanthin (diatoms), zeaxanthin (red algae), and chlorophyll $b$ (green algae), scaled to chlorophyll a (total algae); (Fuco $+\mathrm{Chl} b$ )-Zea: multivariate response representing the coupled marker pigments fucoxanthin (diatoms) and chlorophyll $b$ (green algae), scaled to zeaxanthin (red algae). $\eta^{2}$ : effect size; bold: significant $\mathrm{p}$

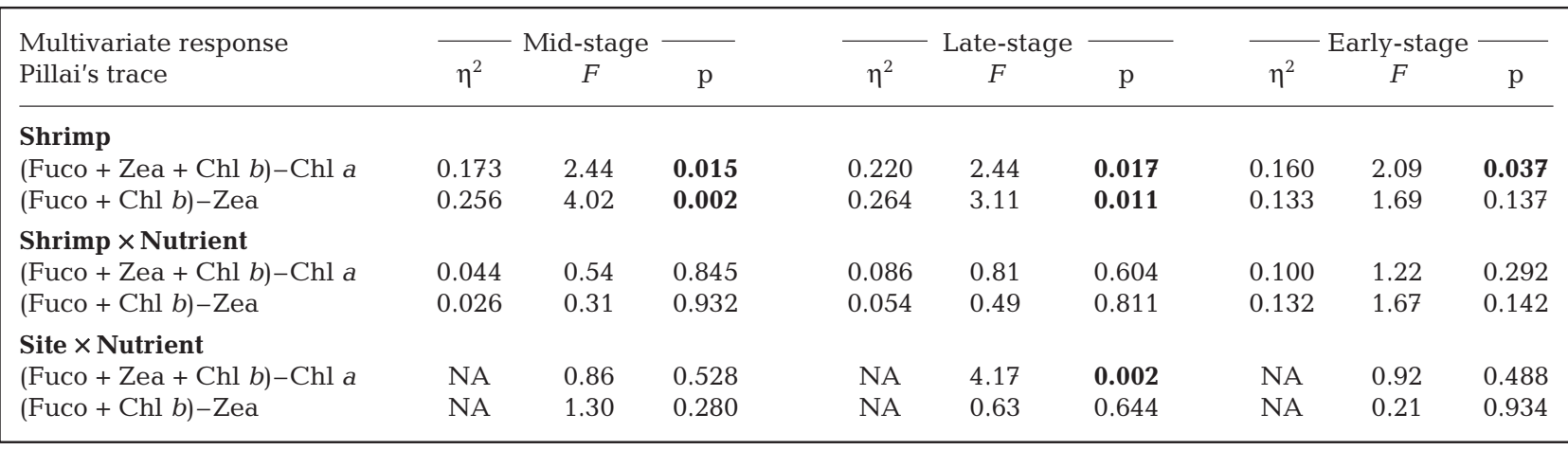


Table 2. Split-plot univariate ANOVAs for the 3 field experiments. Site and nutrient terms belong to the main-plot portion; shrimp, shrimp $\times$ nutrient, and site $\times$ nutrient terms were tested against the split-plot error mean square. $\eta_{\mathrm{p}}^{2}$ : partial Eta squared (effect size); bold: $\mathrm{p}<0.06$; underlined: $\mathrm{p}<0.1$. Fuco-Chl $a$, Zea-Chl $a$, and $\mathrm{Chl} b$-Chl $a$ : responses for the 3 primary marker pigments fucoxanthin (diatoms), zeaxanthin (red algae), and chlorophyll $b$ (green algae), scaled to chlorophyll a (total algae); Zea-Fuco, Chl $b$-Fuco, and Chl $b$-Zea: responses for the 3 coupled pigment variables fucoxanthin (diatoms), zeaxanthin (red algae), and chlorophyll $b$ (green algae), scaled to chlorophyll a (proxy for total epiphytic algae)

\begin{tabular}{|c|c|c|c|c|c|c|c|c|c|}
\hline \multirow{2}{*}{ Response } & \multicolumn{3}{|c|}{ Lid-stage } & \multirow{2}{*}{$\eta_{\mathrm{p}}^{2}$} & \multirow{2}{*}{$\begin{array}{c}\text { Late-stag } \\
\qquad F\end{array}$} & \multirow[b]{2}{*}{$\mathrm{p}$} & \multirow[b]{2}{*}{$\eta_{\mathrm{p}}^{2}$} & \multirow{2}{*}{$\begin{array}{l}\text { Early-stag } \\
\qquad F\end{array}$} & \multirow[b]{2}{*}{$\mathrm{p}$} \\
\hline & $\eta_{\mathrm{p}}^{2}$ & $F$ & $\mathrm{p}$ & & & & & & \\
\hline \multicolumn{10}{|c|}{ Site $($ block $)(\mathrm{df}=2)$} \\
\hline Fuco-Chl a & 0.964 & 26.87 & 0.036 & 0.138 & 0.16 & 0.862 & 0.736 & 2.79 & 0.264 \\
\hline Zea-Chl a & 0.869 & 6.65 & 0.131 & 0.900 & 8.99 & 0.100 & 0.329 & 0.49 & 0.671 \\
\hline Chl $b-\mathrm{Chl} a$ & 0.592 & 1.45 & 0.408 & 0.659 & 1.93 & 0.341 & 0.705 & 2.39 & 0.295 \\
\hline Zea-Fuco & 0.913 & 10.47 & $\underline{0.087}$ & 0.888 & 7.90 & 0.112 & 0.911 & 10.22 & $\underline{0.089}$ \\
\hline Chl $b$-Fuco & 0.506 & 1.02 & $\overline{0.494}$ & 0.344 & 0.53 & 0.656 & 0.911 & 10.20 & $\underline{0.089}$ \\
\hline Chl $b$-Zea & 0.659 & 1.93 & 0.341 & 0.812 & 4.33 & 0.188 & 0.601 & 1.51 & 0.399 \\
\hline \multicolumn{10}{|l|}{ Nutrient $(\mathrm{df}=1)$} \\
\hline Fuco-Chl a & 0.695 & 4.56 & 0.166 & 0.218 & 0.56 & 0.533 & 0.709 & 4.87 & 0.158 \\
\hline Zea-Chl a & 0.088 & 0.19 & 0.703 & 0.847 & 11.08 & $\underline{0.080}$ & 0.501 & 2.01 & 0.292 \\
\hline Chl $b-C h l a$ & 0.285 & 0.80 & 0.466 & 0.003 & 0.01 & 0.949 & 0.077 & 0.17 & 0.722 \\
\hline Zea-Fuco & 0.234 & 0.61 & 0.516 & 0.439 & 1.56 & 0.338 & 0.740 & 5.68 & 0.140 \\
\hline Chl $b$-Fuco & 0.343 & 1.04 & 0.414 & 0.058 & 0.12 & 0.760 & 0.700 & 4.67 & 0.163 \\
\hline Chl $b$-Zea & 0.131 & 0.30 & 0.638 & 0.372 & 1.18 & 0.390 & 0.057 & 0.12 & 0.762 \\
\hline \multicolumn{10}{|c|}{ Site $\times$ Nutrient $(\mathrm{df}=2)$ (main-plot error) } \\
\hline Fuco-Chl a & 0.008 & 0.14 & 0.866 & 0.631 & 22.24 & $<0.001$ & 0.048 & 0.83 & 0.445 \\
\hline Zea-Chl a & 0.063 & 1.19 & 0.318 & 0.010 & 0.13 & 0.876 & 0.060 & 1.05 & 0.362 \\
\hline Chl $b-\mathrm{Chl} a$ & 0.081 & 1.54 & 0.229 & 0.040 & 0.55 & 0.585 & 0.013 & 0.22 & 0.807 \\
\hline Zea-Fuco & 0.060 & 1.12 & 0.337 & 0.018 & 0.24 & 0.785 & 0.014 & 0.24 & 0.791 \\
\hline Chl $b$-Fuco & 0.077 & 1.47 & 0.245 & 0.090 & 1.29 & 0.293 & 0.009 & 0.15 & 0.861 \\
\hline Chl $b-$ Zea & 0.089 & 1.71 & 0.196 & 0.045 & 0.62 & 0.548 & 0.012 & 0.21 & 0.814 \\
\hline \multicolumn{10}{|l|}{ Shrimp $(\mathrm{df}=3)$} \\
\hline Fuco-Chl a & 0.141 & 1.92 & 0.145 & 0.250 & 2.90 & 0.054 & 0.157 & 2.05 & 0.125 \\
\hline Zea-Chl a & 0.242 & 3.72 & 0.020 & 0.265 & 3.12 & 0.043 & 0.248 & 3.63 & 0.023 \\
\hline Chl $b-\mathrm{Chl} a$ & 0.221 & 3.30 & 0.031 & 0.255 & 2.97 & 0.050 & 0.061 & 0.72 & 0.547 \\
\hline Zea-Fuco & 0.290 & 4.76 & 0.007 & 0.219 & 2.43 & $\underline{0.088}$ & 0.194 & 2.64 & $\underline{0.066}$ \\
\hline Chl $b$-Fuco & 0.224 & 3.37 & 0.029 & 0.294 & 3.62 & 0.026 & 0.155 & 2.02 & 0.130 \\
\hline Chl $b$-Zea & 0.270 & 4.32 & 0.011 & 0.511 & 9.07 & $<0.001$ & 0.048 & 0.56 & 0.646 \\
\hline \multicolumn{10}{|c|}{ Shrimp $\times$ Nutrient $(\mathrm{df}=3)$} \\
\hline Fuco-Chl a & 0.037 & 0.45 & 0.716 & 0.147 & 1.49 & 0.241 & 0.133 & 1.68 & 0.190 \\
\hline Zea-Chl a & 0.067 & 0.84 & 0.480 & 0.096 & 0.92 & 0.447 & 0.101 & 1.23 & 0.314 \\
\hline Chl $b-\mathrm{Chl} a$ & 0.020 & 0.24 & 0.867 & 0.044 & 0.40 & 0.752 & 0.124 & 1.56 & 0.217 \\
\hline Zea-Fuco & 0.033 & 0.40 & 0.756 & 0.086 & 0.82 & 0.496 & 0.105 & 1.29 & 0.295 \\
\hline Chl $b$-Fuco & 0.019 & 0.22 & 0.879 & 0.033 & 0.29 & 0.829 & 0.188 & 2.54 & $\underline{0.073}$ \\
\hline Chl $b-Z e a$ & 0.015 & 0.17 & 0.913 & 0.029 & 0.26 & 0.854 & 0.137 & 1.74 & 0.178 \\
\hline Split-plot error & & $\mathbf{d f}=3$ & & & $\mathbf{d f}=2$ & & & $\mathbf{d f}=3$ & \\
\hline
\end{tabular}

chl $b$-fucoxanthin, in the late-stage experiment $\left(C_{1,15}=\right.$ 0.69 to $0.23 ; \mathrm{p}=0.001$ to 0.91 ).

However, variance was heterogeneous among treatment groups for all pigment variables in the earlystage experiment $\left(C_{1,21}=0.68\right.$ to $0.40 ; \mathrm{p}<0.001$ to $0.035)$, albeit heterogeneity was lower for the coupled pigment variables. Tests of overall shrimp effects displayed fairly high power $(\bar{x}=0.617 \pm 0.215 \mathrm{SD}$; range $=$ 0.153 to 0.989 ) across experiments.

Eight specific shrimp-addition or shrimp-density effects on epiphytic pigment variables were significant, and 3 were marginally significant among the 3 experiments (Table 3 ). Effect sizes $\left(\eta^{2}\right)$ for 3 significant and 1 marginally significant shrimp-addition contrasts averaged $0.656 \pm 0.046 \mathrm{SD}$ (range $=0.599$ to 0.771 ) Effect sizes $\left(\eta^{2}\right)$ for 5 significant and 2 marginally significant shrimp-density contrasts averaged $0.692 \pm$ $0.069 \mathrm{SD}$ (range $=0.610$ to 0.797 )

In both mid- and late-stage experiments, red algae visibly decreased in the presence of grass shrimp (Fig. 1). Decreases in red algae (i.e. zeaxanthin) were significant with respect to both shrimp-addition and shrimp-density contrasts in the mid-stage experiment (Table 3). In contrast, relative amounts of red algae (i.e. zeaxanthin) were significantly higher with respect to the shrimp-addition contrast, and marginally signifi- 
Table 3. Planned orthogonal contrasts for pigment variables relative to specific grass shrimp Palaemonetes spp. effects within the split-plot ANOVAs. Contrast effects-Encl: enclosure; Addn: shrimp addition; Dens: shrimp density; bold: $\mathrm{p}<0.06$; underlined: $\mathrm{p}<0.1$; Fuco: fucoxanthin (diatoms); Zea: zeaxanthin (red algae); Chl $b$ : chlorophyll $b$ (green algae); Chl $a$ : chlorophyll a (total epiphytic algae); $\eta^{2}$ : eta-squared (effect size)

\begin{tabular}{|c|c|c|c|c|}
\hline Response & Contrast & $\eta^{2}$ & $t$-value & $\mathrm{p}$ \\
\hline \multicolumn{5}{|l|}{ Mid-stage } \\
\hline \multirow[t]{3}{*}{ Fuco-Chl a } & Encl & 0.156 & 0.609 & 0.547 \\
\hline & Addn & 0.323 & -0.978 & 0.335 \\
\hline & Dens & 0.691 & -2.114 & 0.042 \\
\hline \multirow[t]{3}{*}{ Zea-Chl a } & Encl & 0.663 & 1.985 & 0.055 \\
\hline & Addn & 0.655 & 1.950 & 0.059 \\
\hline & Dens & 0.660 & 1.972 & 0.056 \\
\hline \multirow{3}{*}{ Chl $b-$ Chl $a$} & Encl & 0.812 & -2.941 & 0.006 \\
\hline & Addn & 0.271 & -0.862 & 0.394 \\
\hline & Dens & 0.183 & 0.669 & 0.508 \\
\hline \multirow[t]{3}{*}{ Zea-Fuco } & Encl & 0.516 & 1.460 & 0.153 \\
\hline & Addn & 0.711 & 2.217 & 0.033 \\
\hline & Dens & 0.797 & 2.801 & 0.008 \\
\hline \multirow[t]{3}{*}{ Chl $b$-Fuco } & Encl & 0.806 & -2.880 & 0.007 \\
\hline & Addn & 0.128 & -0.542 & 0.591 \\
\hline & Dens & 0.407 & 1.171 & 0.249 \\
\hline \multirow[t]{3}{*}{ Chl $b$-Zea } & Encl & 0.843 & -3.272 & 0.002 \\
\hline & Addn & 0.540 & -1.533 & 0.134 \\
\hline & Dens & 0.036 & -0.271 & 0.788 \\
\hline \multicolumn{5}{|l|}{ Late-stage } \\
\hline \multirow{3}{*}{ Fuco-Chl a } & Encl & 0.260 & 0.838 & 0.410 \\
\hline & Addn & 0.453 & 1.286 & 0.210 \\
\hline & Dens & 0.746 & -2.427 & 0.022 \\
\hline \multirow[t]{3}{*}{ Zea-Chl a } & Encl & 0.724 & 2.292 & 0.030 \\
\hline & Addn & 0.455 & 1.293 & 0.207 \\
\hline & Dens & 0.378 & -1.102 & 0.280 \\
\hline \multirow[t]{3}{*}{$\mathrm{Chl} b-\mathrm{Chl} a$} & Encl & 0.727 & -2.311 & 0.029 \\
\hline & Addn & 0.228 & -0.769 & 0.449 \\
\hline & Dens & 0.522 & 1.479 & 0.151 \\
\hline \multirow[t]{3}{*}{ Zea-Fuco } & Encl & 0.700 & 2.158 & 0.040 \\
\hline & Addn & 0.368 & 1.079 & 0.291 \\
\hline & Dens & 0.194 & -0.694 & 0.494 \\
\hline \multirow[t]{3}{*}{ Chl $b$-Fuco } & Encl & 0.744 & -2.413 & 0.023 \\
\hline & Addn & 0.302 & -0.931 & 0.360 \\
\hline & Dens & 0.614 & 1.784 & $\underline{0.086}$ \\
\hline \multirow[t]{3}{*}{ Chl $b$-Zea } & Encl & 0.889 & -4.004 & $<0.001$ \\
\hline & Addn & 0.599 & -1.728 & $\underline{0.096}$ \\
\hline & Dens & 0.724 & 2.289 & $\overline{0.030}$ \\
\hline \multicolumn{5}{|l|}{ Early-stage } \\
\hline \multirow[t]{3}{*}{ Fuco-Chl a } & Encl & 0.746 & 2.421 & 0.021 \\
\hline & Addn & 0.141 & -0.572 & 0.571 \\
\hline & Dens & 0.009 & 0.132 & 0.896 \\
\hline \multirow[t]{3}{*}{ Zea-Chl a } & Encl & 0.631 & -1.849 & $\underline{0.073}$ \\
\hline & Addn & 0.661 & -1.976 & 0.056 \\
\hline & Dens & 0.610 & 1.767 & $\underline{0.086}$ \\
\hline \multirow[t]{3}{*}{ Chl $b-\mathrm{Chl} a$} & Encl & 0.480 & -1.359 & 0.183 \\
\hline & Addn & 0.000 & 0.012 & 0.990 \\
\hline & Dens & 0.149 & -0.591 & 0.558 \\
\hline Zea-Fuco & Encl & 0.789 & -2.732 & 0.010 \\
\hline & Addn & 0.031 & -0.252 & 0.802 \\
\hline & Dens & 0.129 & 0.545 & 0.589 \\
\hline Chl $b$-Fuco & Encl & 0.741 & -2.391 & 0.023 \\
\hline & Addn & 0.042 & 0.296 & 0.769 \\
\hline & Dens & 0.144 & -0.580 & 0.566 \\
\hline Chl $b$-Zea & Encl & 0.240 & -0.794 & 0.433 \\
\hline & Addn & 0.095 & 0.457 & 0.651 \\
\hline & Dens & 0.300 & -0.926 & 0.361 \\
\hline
\end{tabular}

cantly lower with respect to the shrimp-density contrast in the early-stage experiment. Non-significant differences in red algae among grass shrimp treatments in the late-stage experiment likely reflect the absence of 6 of the 12 replicates representing the noshrimp treatment, which were missing due to Ruppia maritima die-back. Remarkably, amounts of diatoms increased significantly relative to the shrimp-density contrast in both mid- and late-stage experiments.

Changes in the epiphytic algal community were best expressed in terms of red algae-diatoms relative to shrimp treatments in mid- and late-stage experiments (Fig. 2). Values for red algae-diatoms were significantly lower with respect to both shrimp-addition and shrimp-density contrasts in the mid-stage experiment (Table 3). In contrast, green algae-red algae first increased and then decreased relative to medium and high shrimp treatments in the late-stage experiment, and green algae-diatoms visibly decreased relative to shrimp density in both mid- and late-stage experiments. Values for green algae-red algae were marginally significantly higher with respect to the shrimpaddition contrast and significantly lower with respect to the shrimp-density contrast in the late-stage experiment. Green algae-diatom values were also marginally significantly lower with respect to shrimp density in the late-stage experiment.

Except for a marginally significant shrimp $\times$ nutrient interaction for the green algae-diatom response in the early-stage experiment, shrimp $\times$ nutrient terms were non-significant for all pigment variables across the 3 experiments (Table 2). In general, the early-stage experiment exhibited a somewhat greater propensity for shrimp $\times$ nutrient interactions, as evidenced by relatively low p-values and high effect sizes.

\section{Enclosure effects}

Enclosure effects were significant for 12 of the 18 sets of planned contrasts across the 3 experiments: 3 in the early-stage, 4 in the mid-stage, and 5 in the latestage experiment (Table 3). Effect sizes $\left(\eta^{2}\right)$ for the 12 significant enclosure contrasts averaged $0.765 \pm$ $0.064 \mathrm{SD}$ (range $=0.663$ to 0.889 ). Seven of the 12 significant enclosure effects involved green algae. Three significant shrimp-addition or -density effects accompanied significant enclosure effects: 2 representing relative amounts of red algae in the mid-stage experiment and 1 representing green algae-red algae in the late-stage experiment.

Enclosure effects varied among experiments for different functional groups (Table 3). Enclosure effects were significant for red algae and green algae in both mid- and late-stage experiments, and significant 

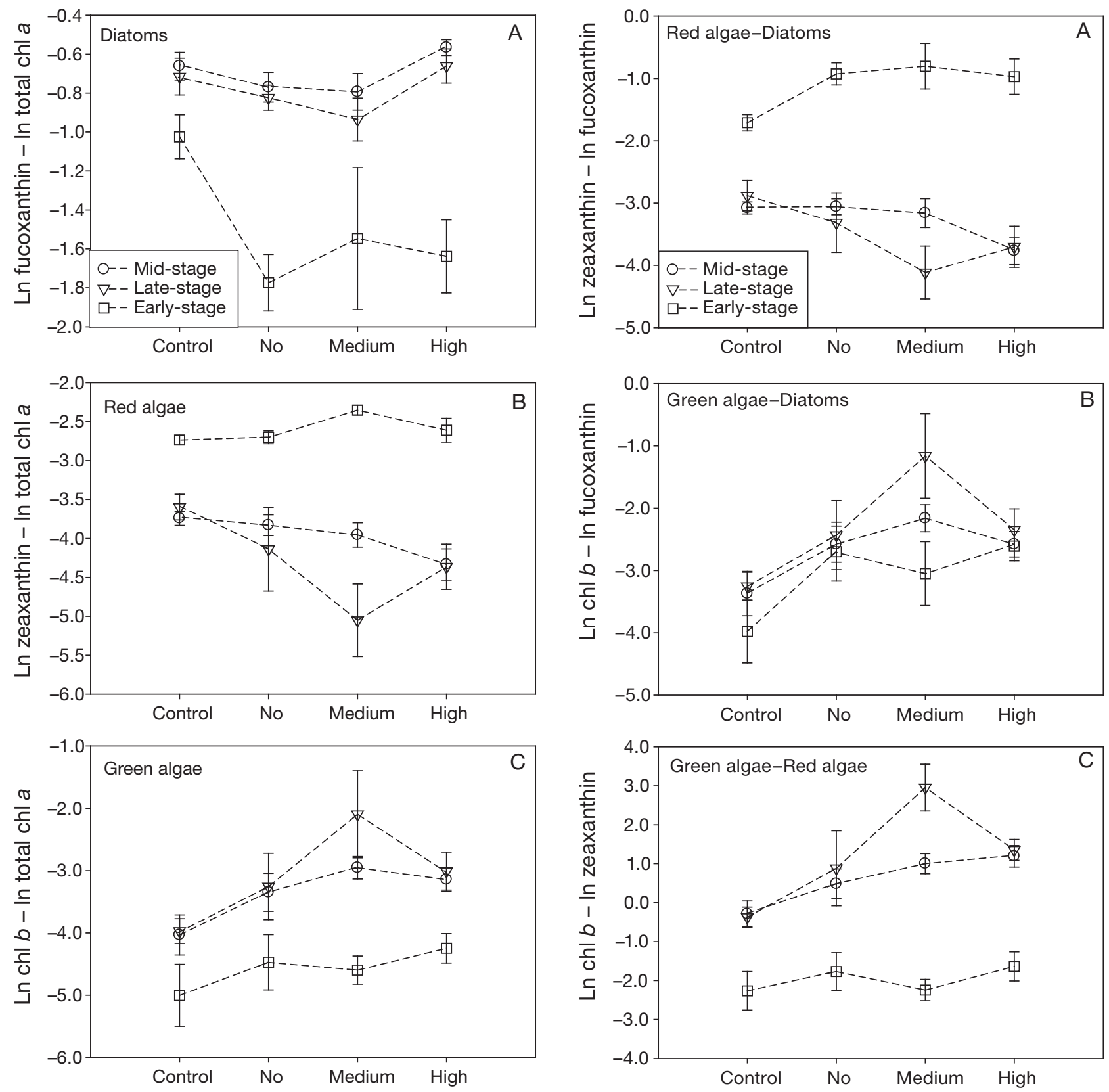

Fig. 1. Fucoxanthin (diatoms) (A), zeaxanthin (red algae) (B), and chl $b$ (green algae) (C) responses (scaled relative to total chl a) across control (ambient) and 3 grass shrimp Palaemonetes spp. treatments (i.e. no, medium, high) for the three $28 \mathrm{~d}$ field experiments

Fig. 2. Zeaxanthin-Fucoxanthin (red algae-diatoms) (A), chl $b$-fucoxanthin (green algae-diatoms) (B), and chl $b$-zeaxanthin (green algae-red algae) (C) responses across control (ambient) and 3 grass shrimp Palaemonetes spp. treatments (i.e. no, medium, high) for the three $28 \mathrm{~d}$ field experiments

for diatoms in the early-stage experiment. Relative amounts of red and green algae were lower and higher, respectively within shrimp enclosure treatments in mid- and late-stage experiments, and relative amounts of diatoms were lower within enclosed treatments in the early-stage experiment (Fig. 1). Values for

green algae-red algae were significantly higher within enclosed shrimp treatments than in the ambient environment in the mid- and late-stage experiments (Table 3). In addition, red algae-diatom values were significantly lower within enclosed shrimp treatments in the late-stage experiment, whereas the directional- 
ity of a significant red algae-diatom enclosure effect was reversed in the early-stage experiment (Fig. 2).

\section{Main plot effects}

\section{Nutrient effects}

Although the overall quantity of epiphytic algae was not enhanced by nutrient addition, except in the earlystage experiment (Drury McCall \& Rakocinski 2007), the composition of the algal community could still have been altered by nutrient addition in any of the experiments. Joint consideration of effect size and significance values aided interpretations of the nutrient main effect, because tests of this effect typically exhibited low power, averaging $0.147 \pm 0.116 \mathrm{SD}$ (range $=0.054$ to 0.450 ) across experiments.

Nutrient-related differences in the 3 marker pigments were not evident, except that diatoms appeared to decrease with nutrient addition in the early-stage experiment (Fig. 3). Although non-significant ( $p=0.158)$, the noticeable decline in diatoms with nutrient addition in this experiment was accompanied by a high partial effect size $\left(\eta_{\mathrm{P}}^{2}\right)$ of 0.709 (Table 2$)$. A marginally significant increase in red algae in response to nutrient addition, accompanied by a high effect size $\left(\eta_{\mathrm{P}}{ }^{2}\right)$ of 0.847 , occurred in the late-stage experiment. Green algae did not differ relative to nutrient addition in any of the experiments.

Nutrient-related differences in the coupled pigments were mixed. An increase in red algae-diatoms relative to nutrient addition in the early-stage experiment was supported by a combination of values for $\mathrm{p}$ of 0.140 and for effect size $\left(\eta_{\mathrm{P}}{ }^{2}\right)$ of 0.740 (Table 2). Although highly variable within experiments, mean green algaediatom values consistently increased with nutrient addition in all 3 experiments (Fig. 4). However, green algae-red algae values were clearly unaffected by nutrient addition in all of the experiments.

\section{Site effects}

As a main-plot term, univariate tests of the site effect were not very powerful, averaging $0.250 \pm 0.187 \mathrm{SD}$ (range $=0.055$ to 0.750 ) across experiments. Overall, a significant among-site difference in diatoms occurred in the mid-stage experiment, and marginally significant among-site differences in red algae-diatom values occurred in both the mid- and early-stage experiments (Table 2). Despite few significant site effects, generally large effect sizes $\left(\eta_{\mathrm{P}}^{2}\right)($ mean $=0.691 \pm 0.238$ $\mathrm{SD}$; range $=0.138$ to 0.964 ) for the site factor across experiments confirmed that spatial variability in the pigment variables existed.
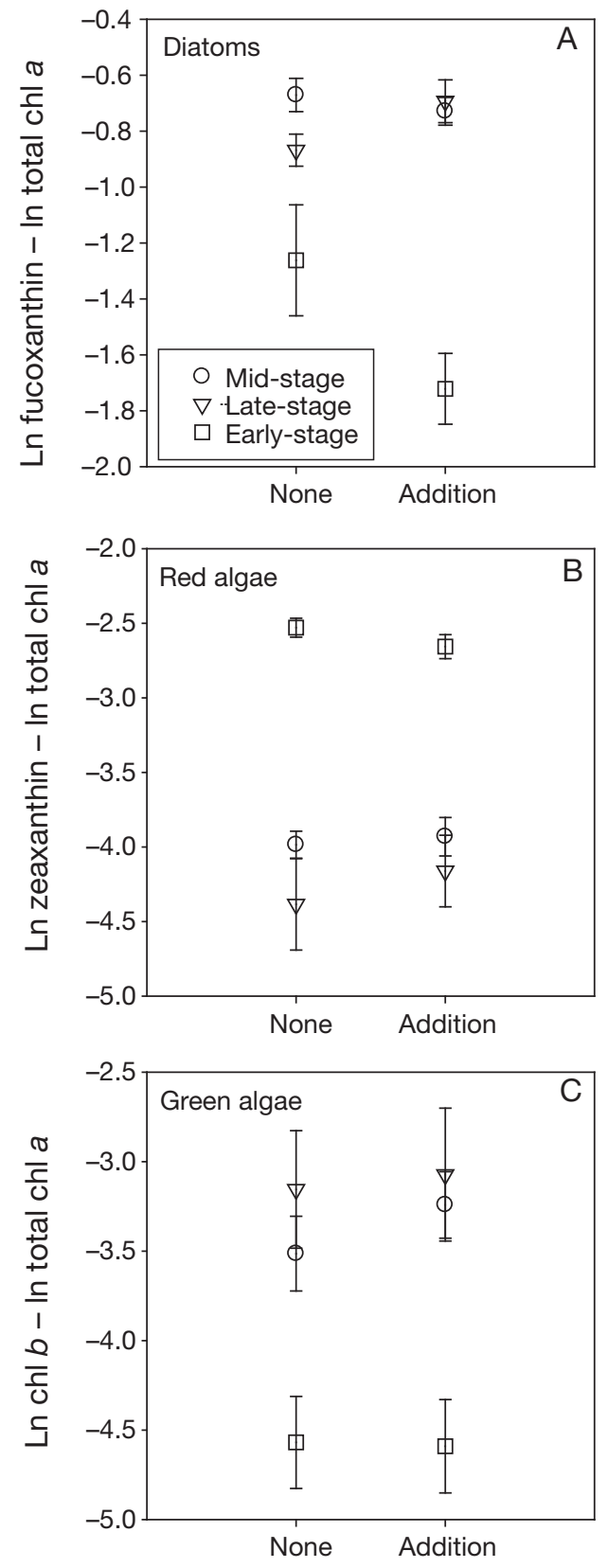

Fig. 3. Fucoxanthin (diatoms) (A), zeaxanthin (red algae) (B), and $\mathrm{chl} b$ (green algae) (C) responses (scaled relative to total chl a) to unfertilized (none) and nutrient-enriched (addition) treatments for the three $28 \mathrm{~d}$ field experiments

\section{DISCUSSION}

In the present study, we examined responses by the algal epiphyte community to grass shrimp Palaemonetes spp. and nutrient addition during 3 growth stages of the ephemeral host macrophyte Ruppia maritima. In a previous study (Drury McCall \& Rakocinski 2007), we found that during mid- and late $R$. maritima growth 

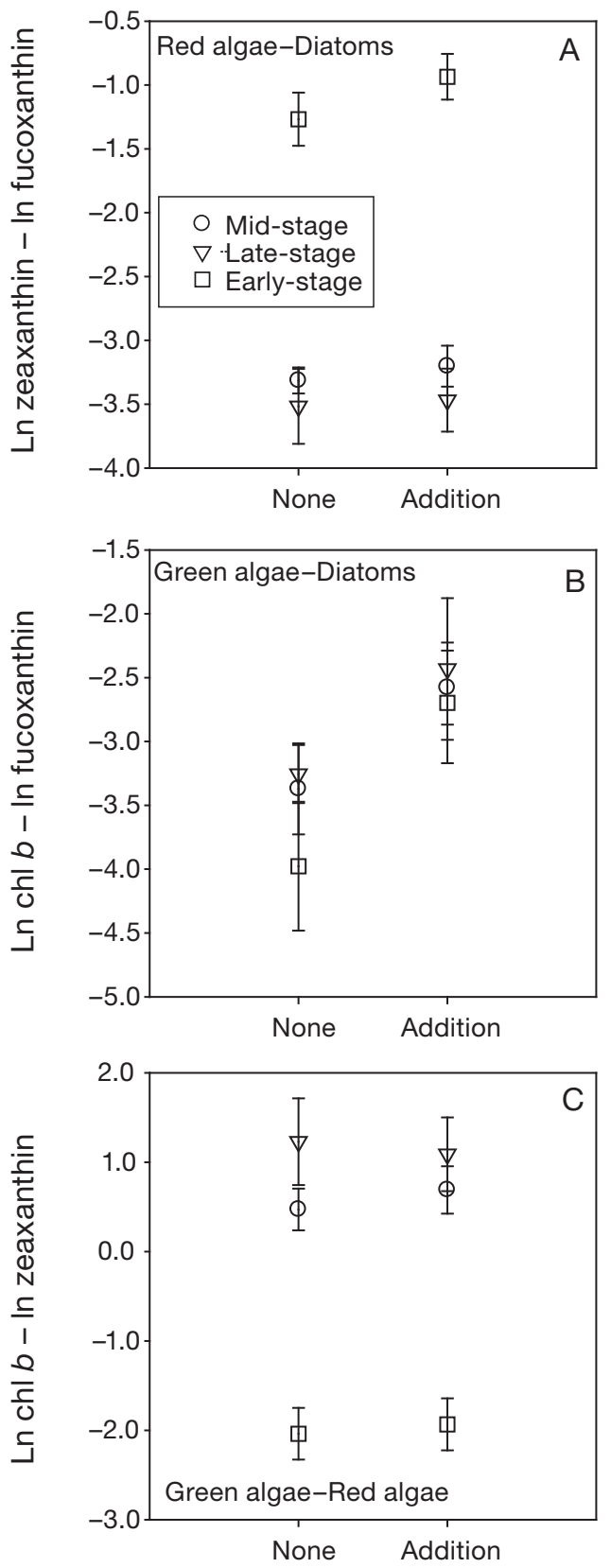

Fig. 4. Zeaxanthin-Fucoxanthin (red algae-diatoms) (A), chl $b$-fucoxanthin (green algae-diatoms) (B), and chl $b$-zeaxanthin (green algae-red algae) (C) responses to unfertilized (none) and nutrient-enriched (addition) treatments for the three $28 \mathrm{~d}$ field experiments

stages, grass shrimp reduced overall loads of epiphytic algae. Moreover, during the early-growth stage, nutrient addition enhanced overall epiphytic loading, while grass shrimp effects on epiphytic loading were negligible. In a previous study of grazer and nutrient addition effects on the epiphyte community of Zostera marina, isopod and amphipod grazers selectively re- duced epiphytic diatoms, while nutrients increased cyanobacteria (Neckles et al. 1994). In the present study, facultative grazing by grass shrimp directly reduced red algae, and possibly indirectly altered interactions among the epiphyte groups. Grass shrimp appeared to have more pronounced effects on $R$. maritima epiphyte functional group composition than nutrient addition, especially during mid- and lategrowth stages. Nutrient-induced changes in marker pigments were nominal, despite a broad interpretation of nutrient effects involving joint consideration of $p$ and $\eta_{\mathrm{P}}{ }^{2}$ values. However, nutrient-addition effects on epiphyte composition were most apparent during the early-stage experiment, when shrimp effects on epiphyte composition were minor. Except for a modest but significant increase in red algae relative to the addition of shrimp, epiphyte groups did not respond noticeably to the presence of shrimp in the early-stage experiment. Ironically, this general positive effect of grass shrimp on red algae in the early-stage experiment cannot be explained by direct facultative grazing, notwithstanding the mean being marginally significantly lower for the high-shrimp with respect to the mediumshrimp treatment.

\section{Grass shrimp effects on Ruppia maritima epiphytes}

Relatively low amounts of epiphytic algae may help explain the lack of detectable facultative grazing by grass shrimp in the early-stage experiment. Ambient amounts of epiphytic algae were ca. 2- to 3-fold lower and more variable in the early-stage experiment than in the mid- and late-stage experiments (Drury McCall \& Rakocinski 2007). Low water temperatures, along with less time for the build up of epiphytic algae on new $R$. maritima growth might, in turn, help explain less profuse epiphytic loads in spring. Mean water temperature during the early-stage experiment $\left(26.2^{\circ} \mathrm{C}\right)$ was markedly lower than the mean temperature for mid- and late-stage experiments $\left(30.3^{\circ} \mathrm{C}\right)$, implying reduced shrimp effects: the grazing rate of grass shrimp at $26^{\circ} \mathrm{C}$ should be $\sim 40 \mathrm{mg}$ epiphytes $\mathrm{mg}^{-1}$ shrimp $\mathrm{h}^{-1}$, whereas at $30^{\circ} \mathrm{C}$ the rate should be $\sim 59 \mathrm{mg}$ epiphytes $\mathrm{mg}^{-1}$ shrimp $^{-1}$ (Morgan 1980).

Grass shrimp addition visibly influenced red algae and diatoms in both mid- and late-stage experiments. In the mid-stage experiment, shrimp effects were manifested as a significant decrease in relative amounts of red algae relative to shrimp addition and high shrimp density, as well as a significant increase in diatoms relative to shrimp density. Furthermore, strong significant decreases in the coupled red algae-diatom response relative to both shrimp addition and density in the midstage experiment implied complementary interactions 
between these 2 functional groups. Changes in relative amounts of red algae and diatoms across shrimp treatments in the late-stage experiment paralleled those in the mid-stage experiment; however, enhanced variability attributed to the onset of senescence likely precluded significant differences in red algae. In this experiment, half of the replicates for the no-shrimp treatment were missing due to complete lack of Ruppia maritima, suggesting an exacerbated SAV condition in the no-shrimp treatment (Drury McCall \& Rakocinski 2007). The marked loss of replicates from the noshrimp treatment in the late-stage experiment is consistent with an interpretation based on the onset of early senescence due to epiphyte overgrowth (Kantrud 1991). Notwithstanding, a significant increase in diatoms between the medium- and high-shrimp treatments in the late-stage experiment further supports the complementary relationship between the functional groups. Hillebrand et al. (2000) documented a grazer-induced competitive-release mechanism resulting in an increase in Licomorpha abbreviate when occurring in the presence of a preferred epiphyte. Less apparent direct effects of shrimp grazing on diatoms could also partly reflect faster turnover rates of this functional group compared to those of red algae. A significant decrease in the coupled green algae-red algae response relative to shrimp density in the latestage experiment might reflect secondary utilization of green algae by grass shrimp, as total amounts of epiphytic red algae were low due to SAV senescence. Alternatively, this shift might also reflect the indirect effects of grass shrimp on biotic interactions between algal groups.

Selective grazing by grass shrimp was inferred as an agent of change on the epiphyte community during the mid- and late Ruppia maritima growth stages. Removal of epiphytes through mechanical disturbance by grass shrimp was unlikely, because shrimp effects were stronger on epiphyte chl a than on total epibiota mass (Drury 2004). Diets of Palaemonetes spp. from Halodule wrightii and Spartina alterniflora reveal consumption of diatom, red algal, and green algal epiphytes (Morgan \& Kitting 1984, Quiñones-Rivera \& Fleeger 2005). Thus, selective grazing of red algal epiphytes by grass shrimp may reflect algal morphology as much as palatability. Because of its erect, branching morphology, red algae such as Polysiphonia spp. may be selected over other algal groups, especially by relatively large facultative grazers like grass shrimp. A mechanical explanation for selective grazing of red algae is also consistent with the finding that epiphytes on $S$. alterniflora are grazed opportunistically by grass shrimp (Quiñones-Rivera \& Fleeger 2005). In a study of grazer and nutrient effects on a benthic microalgal community in the western Baltic Sea, erect microalgae were preferred by gastropod, amphipod and isopod grazers (Hillebrand et al. 2000).

\section{Nutrient-addition effects on Ruppia maritima epiphytes}

Although other studies often document distinct changes in the composition of the epiphyte community related to nutrient enrichment (Hillebrand \& Sommer 1997, Wear et al. 1999, Armitage et al. 2005), changes in the epiphyte community relative to nutrient addition were modest and variable in our experiments. Mean green algae-diatom values visibly increased with nutrient addition in all 3 experiments. Also, relative amounts of diatoms decreased visibly with nutrient addition in the early-stage experiment. Nutrient effects on epiphyte composition in the early-stage experiment also coincided with a distinct nutrient-related increase in the total amount of algal epiphytes (Drury McCall \& Rakocinski 2007). The lack of significant shrimp $\times$ nutrient interactions across all 3 experiments reflects largely independent effects of both factors on epiphyte composition.

\section{Enclosure effects}

Planned orthogonal contrasts revealed notable enclosure effects on algal pigment responses. Despite efforts to minimize enclosure effects through design and maintenance, experimental cylinders likely altered the light and hydrographical conditions experienced by epiphytic algae. In addition, enclosure effects also possibly reflect certain biases related to grass shrimp addition, such as competition among shrimp, restricted movement, restricted food choice, and the lack of predation effects (see Drury McCall \& Rakocinski 2007, Appendices $\mathrm{J}$ to $\mathrm{L}$ ). In a recent field experiment by Douglass et al. (2007), light attenuation, reduced water flow, and restricted grazer and predator movements inside enclosures led to lower eelgrass biomass inside enclosures than in unenclosed plots.

In another recent study of grazer and nutrient effects on periphyton, Hillebrand \& Kahlert (2001) found reduced quantities of filamentous algae inside cages. The authors concluded that green algal propagules were hindered from colonizing enclosed epilithic habitats. In contrast, conditions in our study likely favored relatively higher amounts of green algae inside cylinders than in control plots, especially in mid- and latestage experiments. Protection from disturbance by wind and currents may have favored the growth of green algae inside experimental cylinders. Relative amounts of red algae were correspondingly lower 
inside enclosures in mid- and late-stage experiments. However, grass shrimp appeared to selectively graze red algae despite generally lower relative amounts inside enclosures. In the early-stage experiment, relative amounts of diatoms were distinctly lower inside enclosures, perhaps partly explaining why diatoms appeared unresponsive to effects of shrimp addition in this experiment.

\section{Spatio-temporal effects}

Without additional experiments involving multiple instances of early-, mid-, and late-stage Ruppia maritima growth, the extent of spatio-temporal context dependence in epiphyte community responses cannot be fully discerned. Considerable spatial variability in the relative amounts of epiphytic diatoms was revealed by a significant site effect in the mid-stage experiment, as well as by a significant site $\times$ nutrient interaction in the late-stage experiment. Relatively high effect sizes for the site factor across experiments also indicate landscape-scale spatial variability in epiphyte responses. Year-to-year differences should also exist in responses of epiphyte communities, for example, relative to annual discharge regimes. However, confounding effects of site and year should be minimal in our experiments, which were conducted in sufficient proximity in space and time to represent responses by the same R. maritima subsystem.

\section{Conclusions}

As an ephemeral engineering species (Jones et al. 1994), Ruppia maritima concentrates resources, fosters biological production, and provides living space within an estuary. Grass shrimp promote the condition of submerged vegetation through facultative grazing on epiphytic algae and nutrient translocation to sediments (Drury McCall \& Rakocinski 2007). Results of the present study show that grass shrimp can modify the composition of the epiphytic algal community directly; by selectively grazing certain epiphytes, and indirectly; by altering interactions among algal groups. Similar changes in epiphyte composition through selective grazing have been observed in freshwater systems; for example, the chironomid Psectrocladius sp. alters epiphytic algal assemblages through selective grazing (Botts 1993). However, our study also underscores how effects of facultative grazers like grass shrimp are context dependent; for example, depending on the life stage of the SAV, season, and nutrient status. These varied effects reflect the inherent plasticity and complexity of the trophic role played by grass shrimp within different ecological settings. This same flexibility ensures that facultative grazers such as grass shrimp help maintain the diversity and function of the structured habitats they inhabit.

Acknowledgements. We acknowledge the National Oceanic Atmospheric Administration for funding through NOAA National Estuary Research Reserve graduate student fellowship No. NA07OR0258. Sincere appreciation to: Drs B. Comyns, R. Heard, K. Heck, Jr., C. Moncreiff, and M. Sullivan; to Mr. J. D. Caldwell of the USM GCRL Botany section for instruction and equipment; and to Dr. R. McCall and Mr. G. Zapfe for their steadfast assistance with the project.

\section{LITERATURE CITED}

Armitage AR, Frankovich TA, Heck KL Jr, Fourqurean JW (2005) Experimental nutrient enrichment causes complex changes in seagrass, microalgae, and macroalgae community structure in Florida Bay. Estuaries 28:422-434

> Botts PS (1993) The impact of small chironomid grazers on epiphytic algal abundance and dispersion. Freshw Biol 30: $25-33$

Douglass JD, Duffy JE, Spivak AC, Richardson JP (2007) Nutrient vs. consumer control of community structure in a Chesapeake Bay eelgrass habitat. Mar Ecol Prog Ser 348: 71-83

Drury DM (2004) Effects of grass shrimp (Palaemonetes spp.) density manipulations and nutrient enrichment on widgeongrass (Ruppia maritima) condition, epiphyte load, and epiphyte functional groups. PhD dissertation, University of Southern Mississippi, Hattiesburg, MS

Drury McCall D, Rakocinski CF (2007) Grass shrimp (Palaemonetes spp.) play a pivotal trophic role in enhancing Ruppia maritima. Ecology 88:618-624

Duffy JE, Macdonald KS, Rhode JM, Parker JD (2001) Grazer diversity, functional redundancy, and productivity in seagrass beds: an experimental test. Ecology 82:2417-2434

Elston DA, Illius AW, Gordon IJ (1996) Assessment of preference among a range of options using log ratio analysis. Ecology 77:2538-2548

Fleeger JW, Carman KR, Webb S, Hilbun N, Pace MC (1999) Consumption of microalgae by the grass shrimp Palaemonetes pugio. J Crustac Biol 19:324-336

Hillebrand H, Kahlert M (2001) Effect of grazing and nutrient supply on periphyton biomass and nutrient stoichiometry in habitats of different productivity. Limnol Oceanogr 46: 1881-1898

> Hillebrand H, Sommer U (1997) Response of epilithic microphytobenthos of the western Baltic Sea to in situ experiments with nutrient enrichment. Mar Ecol Prog Ser 160: $35-46$

> Hillebrand H, Worm B, Lotze HK (2000) Marine microbenthic community structure regulated by nitrogen loading and grazing pressure. Mar Ecol Prog Ser 204:27-38

Jernakoff P, Brearley A, Nielsen J (1996) Factors affecting grazer-epiphyte interactions in temperate seagrass meadows. Oceanogr Mar Biol Annu Rev 34:109-162

Johannes RE, Satomi M (1966) Composition and nutritive value of fecal pellets of a marine crustacean. Limnol Oceanogr 11:191-197

Jones CG, Lawton JH, Shachak M (1994) Organisms as ecosystem engineers. Oikos 69:373-386

Kantrud HA (1991) Widgeongrass (Ruppia maritima L.): a literature review. Research Publication No. 10, US Fish and Wildlife Service, Washington, DC 
Mantoura RFC, Llewellyn CA (1983) The rapid determination of algal chlorophyll and carotenoid pigments and their breakdown products in natural waters by reverse-phase high performance liquid chromatography. Anal Chim Acta 151:297-314

Mead R, Curnow RN, Hasted AM (2003) Statistical methods in agriculture and experimental biology, 3rd edn. Chapman \& Hall/CRC, New York

Moncreiff CA, Sullivan MJ, Daehnick AE (1992) Primary production dynamics in seagrass beds of Mississippi Sound: the contributions of seagrass, epiphytic algae, sand microflora, and phytoplankton. Mar Ecol Prog Ser 87:161-171

Morgan MD (1980) Grazing and predation of the grass shrimp Palaemonetes pugio. Limnol Oceanogr 25:896-902

Morgan MD, Kitting CL (1984) Productivity and utilization of the seagrass Halodule wrightii and its attached epiphytes. Limnol Oceanogr 29:1066-1076

> Neckles HA, Wetzel RL, Orth RJ (1993) Relative effects of nutrient enrichment and grazing on epiphyte-macrophyte (Zostera marina L.) dynamics. Oecologia 93:285-295

Neckles HA, Koepfler ET, Haas LW, Wetzel RL, Orth RJ (1994) Dynamics of epiphytic photoautotrophs and heterotrophs in Zostera marina (eelgrass) microcosms: responses to nutrient enrichment and grazing. Estuaries 17:597-605

Pinckney JL, Micheli F (1998) Microalgae on seagrass mimics: does epiphyte community structure differ from live seagrasses? J Exp Mar Biol Ecol 221:59-70

Pinckney JL, Millie DF, Howe KE, Paerl HW, Hurley JP (1996) Flow scintillation counting of ${ }^{14} \mathrm{C}$-labeled microalgal photosynthetic pigments. J Plankton Res 18:1867-1880

Quinn GP, Keough MJ (2002) Experimental design and data analysis for biologists. Cambridge University Press, Cambridge

Quiñones-Rivera ZJ, Fleeger JW (2005) The grazing effects of

Editorial responsibility: Just Cebrian,

Dauphin Island, Alabama, USA grass shrimp, Palaemonetes pugio, on epiphytic microalgae associated with Spartina alterniflora. Estuaries 28: $274-285$

Schedl A (1998) Log ratio methods for establishing a reference frame for chemical change. J Geol 106:211-228

Sokal RR, Rohlf JF (1981) Biometry: the principles and practice of statistics in biological research, 2 nd edn. W.H. Freeman and Company, New York

Sullivan MJ (1977) Structural characteristics of a diatom community epiphytic on Ruppia maritima. Hydrobiologia 53: 81-86

van Heukelem L, Lewitus AJ, Kana TM, Craft NE (1992) High-performance liquid chromatography of phytoplankton pigments using a polymeric reversed-phase $\mathrm{C}_{18}$ column. J Phycol 28:867-872

$>$ van Heukelem L, Lewitus AJ, Kana TM, Craft NE (1994) Improved separations of phytoplankton pigments using temperature-controlled high performance liquid chromatography. Mar Ecol Prog Ser 114:303-313

> van Montfrans J, Wetzel RL, Orth RJ (1984) Epiphyte-grazer relationships in seagrass meadows: consequences for seagrass growth and production. Estuaries 7(4A):289-309

> Wear DJ, Sullivan MJ, Moore AD, Millie DF (1999) Effects of water-column enrichment on the production dynamics of three seagrass species and their epiphytic algae. Mar Ecol Prog Ser 179:201-213

- Welsh BL (1975) The role of grass shrimp, Palaemonetes pugio, in a tidal marsh ecosystem. Ecology 56:513-530

Williams SL, Heck KL Jr (2001) Seagrass community ecology. In: Bertness MD, Gaines SD, Hay ME (eds) Marine community ecology. Sinauer Associates, Inc., Sunderland, MA

Williams SL, Ruckelshaus MH (1993) Effects of nitrogen availability and herbivory on eelgrass (Zostera marina) and epiphytes. Ecology 74:904-918

Submitted: January 14, 2008; Accepted: December 2, 2008 Proofs received from author(s): March 11, 2009 